\title{
Repair of Oronasal fistula with Split-thickness Palatal graft.
}

\author{
Dr. Swapnil Moghe ${ }^{1}$, Dr. M.K. Gupta ${ }^{2}$, Dr. Ajay Pillai ${ }^{3}$, Dr. Saksham Nahar ${ }^{4}$, \\ Dr. Amardeep Arun ${ }^{5}$. \\ ${ }^{I}$ (Reader, Department of Oral \& Maxillofacial Surgery, People's Dental Academy, Bhopal, India) \\ ${ }^{2}$ (Professor, Dean \& H.O.D., Department of Oral \& Maxillofacial Surgery, People’s Dental Academy, Bhopal, \\ India) \\ ${ }^{3}$ (Reader, Department of Oral \& Maxillofacial Surgery, People's Dental Academy, Bhopal, India) \\ ${ }^{4,5}$ (PG Student, Department of Oral \& Maxillofacial Surgery, People's Dental Academy, Bhopal, India)
}

\begin{abstract}
A graft is a non-living material or living tissue used for implantation or transplantation to replace a diseased part or compensate for a defect. We repaired a case with an oronasal fistula using split thickness palatal graft on oral side. A 55-year-old man presented an oronasal fistula of the hard palate, measuring $1.0 x$ $1.2 \mathrm{~cm}$. The fistula was $2 \mathrm{~cm}$ posterior to the incisive foramen. The scar tissue around the fistula was unhealthy. A laterally based oral mucosal flap, $2.0 \times 1.5 \mathrm{~cm}$, was designed, raised, and transposed to the defect. The secondary defect was covered with palatal plate. The oral mucosal flap was viable, and no sign of recurrence of fistula was noted until one month postoperative. This method can be an alternative in repair of the oronasal defect when any local tissue for repair is not available or insufficient.
\end{abstract}

Key Words: Oro Nasal Fistula, Palatal Graft

\section{Introduction}

It might seem intriguing how a pea-sized air space at the time of birth within the body of maxilla transforms into a full blown cavity encompassing maximum portion of the body of maxilla. This is made possible by the process of pneumatization which happens to be an evolutionary process as a functional and adaptive phenomenon.

One of the clinical complications encountered by oral and maxillofacial surgeons is oroantral communication (OAC) with progressive formation of oroantral fistula (OAF). The incidence of this complication may vary from 0.31 to $3.8 \%$ after extraction of maxillary teeth ${ }^{1}$.

An OAF of less than $2 \mathrm{~mm}$ diameter has the possibility of spontaneous healing; but in the one with a diameter of more than $3 \mathrm{~mm}$ spontaneous healing is hampered because of inflammation of the sinus or periodontal region ${ }^{2}$. There is also less possibility of spontaneous healing when the OAF has been present for 3-4 weeks, or when its diameter is greater than $5 \mathrm{~mm}^{3}$.If oroantral opening remains untreated, the patients experience sinusitis.

Various techniques and treatment modalities have been described for the management of OAC or OAF.

The few techniques are buccal flap, palatal flap, soft palate flap and related modifications ${ }^{4}$. These techniques have various advantages and disadvantages. The advantage of the buccal flap method is that it can be used when the alveolar ridge is very low and when it is impossible to apply the method of interseptal alveotomy, but buccal flap reduces the depth of the vestibular sulcus, and therefore needs for a vestibuloplasty. A palatal flap of full thickness enables the closure of a fistula opening with the mucous membrane of the hard palate. Palatal flap contains blood vessels which enable a good blood supply, and with its thickness and width, it covers the site of the fistula better and safer. An advantage of this method compared to the buccal flap method is that no lowering of the vestibule occurs and the flap is firmer and more resistant to trauma and infection ${ }^{5}$.Disadvantages of this method are the denudation of the palatal surface, pain, and the later appearance of roughness and deepening of this area as a result of secondary epithelization over 2-3 months. The unpleasant complication is necrosis of the palatal flap ${ }^{6}$.

Recently, third molar transplantation as a technique in closure of OAC has been used. This proposed modality of treatment is promising and unique but has the disadvantage of known complications of third molar extraction. OAF cannot be closed in this manner. Root canal treatment of the transplanted tooth is indicated ${ }^{7}$.

Different types of materials have been used to repair of the oroantral defect. Goldman ${ }^{8}$ applied gold foil to ensure stability of the flap while closing the fistula and prevent possible recurrences. Zide and Karas ${ }^{9}$ used blocks of hydroxyapatite for closure of OAF to fill the bone defect in the alveoli.

Other varieties of graft materials have been used in place of bone, including tantalum ${ }^{8}$, freeze-dried collagen ${ }^{10}$ and fascia lata, Duramater ${ }^{11}$. An OAC was closed by applying a buccal fat pad (BFP)-pedicle BFP graft $^{2}$. It is used in patients with a fistula of $8-20 \mathrm{~mm}$ in diameter. Over a period of 3 weeks, the fatty tissue converts into granulation tissue and epithelizes, which has been confirmed by documented histologic findings. 
Bio-Gide is a synthesized collagen membrane. The porous surface facing the bone allows the in-growth of bone-forming cells. Bio-Oss is a safe and effective bone graft material, very similar to human bone, and highly successful in new bone formation. Due to high purity, no allergic reaction or infection is observed ${ }^{10}$

We used split thickness palatal graft for closure of Oro nasal fistula in the anterior part of palate $\&$ the results were encouraging.

\section{Case Report}

We report a 55-years-old male patient who was referred to the department of Oral \& Maxillofacial Surgery, for the presence of sporadic intraoral drainage of palate. The discomfort was of a few days duration and had its origin following a road traffic accident, which led to Lefort II \#. The radiograph shows no characteristics of OAC/OAF. The patient reported water \& food regurgitation through nose after open reduction internal fixation for Le fort II \#. The earlier approximation of palatal tissues in the midline was done by freshening of palatal margins \& placement of two vertical releasing incisions, but Oro nasal fistula recur within 7 days. The figure 1 shows oronasal fistula defect. The removal of fistulous tract was done as seen in figure 2 . The Split thickness palatal graft of $2 \times 1.5 \mathrm{~cm}$ was harvested from the anterior portion of hard palate (figure 3) $\&$ defect was closed with the graft \& stabilized with 3-0 vicryl suture. The grafted site after placement of palatal plate as seen in figure 4 . Follow up after 1 week was uneventful \& healing was satisfactory as seen in figure 5.There was no sign of recurrence on 1 month follow up (Figure 6). The healing on the grafted site was uneventful \& the donor site healed by secondary intention.

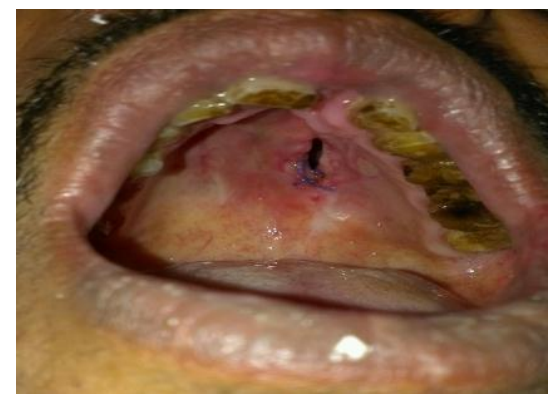

Figure 1:Oronasal fistula defect

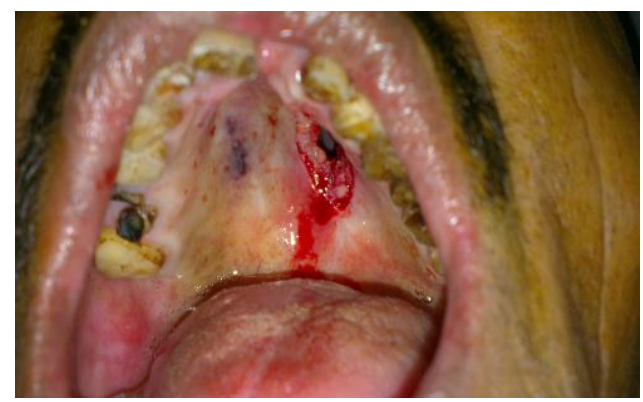

Figure 2: Removal of fistulous tract

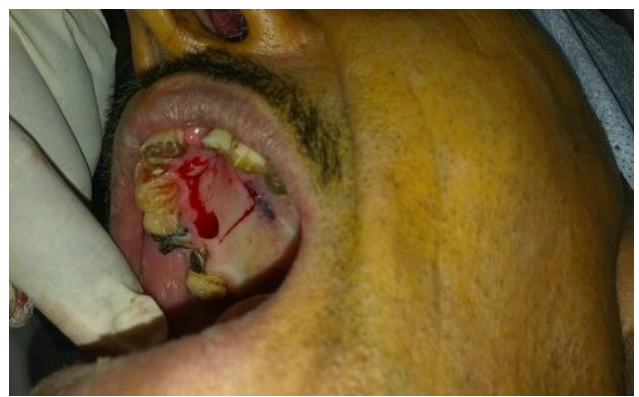

Figure 3:Harvesting of split thickness palatal graft.


Figure 4: Grafted site covered with

Figure5: Follow up picture after 1 week prefabricated palatal plate template. 


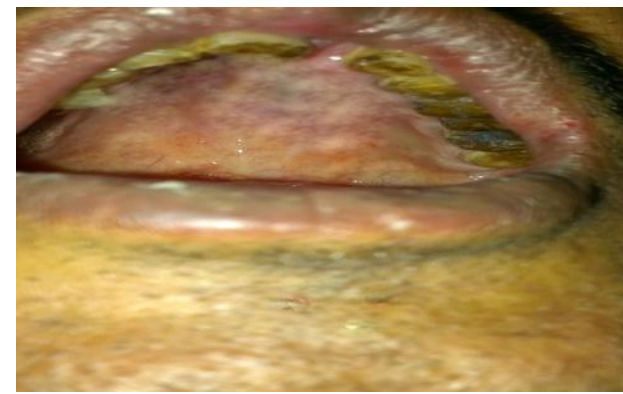

Figure 6: Follow up picture after 1 month Illustrates healed fistula.

III. Discussion:

Periapical periodontitis may result in maxillary sinusitis of dental origin with resultant inflammation and thickening of the mucosal lining of the sinus in areas adjacent to the involved teeth ${ }^{12}$.

This inflammation may be a consequence of over instrumentation and inadvertent injection or extrusion of irrigants, intracanal medicaments, sealers or solid obturation materials.Furthermore, endodontic surgery performed on maxillary teeth may result in sinus perforation that develop into $\mathrm{OAC}^{12}$, than into OAF.

Numerous surgical techniques introduced to close OAC and OAF include rotating or advancing local tissues such as the buccal or palatal mucosa, buccal fat pad, sub mucosal tissue, or tongue tissue ${ }^{13}$.Most of them rely on mobilizing the tissue and advancing the resultant flap into the defect ${ }^{14}$.

The closure of OAF is a major problem considering the phlogistic consequences of sinus membrane infection, with the impossibility to perform implant rehabilitation and pre-implant surgical procedures. In addition, further implant surgery generally requires more reconstructed bone at the implantation site with a monocortical block. The final result is a vascularized new bone formation which eventually Osseo-integrated with the surrounding bone.

Moreover, experimental studies confirm that autogenous bone graft assure more predictable results than xenogenous graft, in term of Osseo-integration on the receiving site, in order to obtain the closure of OAC, such as synthetic bone graft substitutes constitute a valid alternative to flap based techniques ${ }^{15-18}$.

The bone graft techniques for the treatment of moderate to large OAC or OAF demonstrate to be innovative, successful and predictable and permit to avoid the clinical collateral effects, like morbidity of the donor site, related to soft tissue flaps.

These techniques, similar to the one that we reported, were innovative and successful for treating moderate to large ONF.

\section{Conclusion}

ONF should be treated by establishing a physical barrier to prevent infection.

\section{References}

[1]. Punwutikorn J, Waikakul A, Pairuchvej V. Clinically significant oroantral communications--a study of incidence and site. Int J Oral Maxillofac Surg. 1994; 23:19-21.

[2]. Hanazawa Y, Itoh K, Mabashi T, Sato K. Closure of oroantral communications using a pedicled buccal fat pad graft. J Oral Maxillofac Surg. 1995; 53:771-6.

[3]. Martensson G. Operative method in fistulas to the maxillary sinus. Acta Otolaryngol. 1957; 48:253-4.

[4]. Kraut RA, Smith RV. Team approach for closure of oroantral and oronasal fistule. Atlas Oral Maxillofac Surg Clin North Am. 2000;8: 55-75.

[5]. Ehrl PA. Oroantral communication: Epicritical study of 175 patients, with special concern to secondary operative closure. Int J Oral Surg. 1980;9: 351-8

[6]. Solker K, Vuksan V, Lauc T. Treatment of oroantral fistula. Acta Stomatol Croat. 2002; 36:135-40.

[7]. Kitagawa Y, Sano K, Nakamura M, Ogasawara T. Use of third molar transplantation for closure of the oroantral communication after tooth extraction: A report of 2 cases. Oral Surg Oral Med Oral Pathol Oral Radiol Endod. 2003; 95:409-15.

[8]. Goldman EH, Stratigos GT, Arthur AL. Treatment of oroantral fistula by gold foil closure: Report of case. J Oral Surg. 1969; 27:875-7.

[9]. Zide MF, Karas ND. Hydroxylapatite block closure of oroantral fistulas: Report of cases. J Oral Maxillofac Surg. 1992; 50:71-5

[10]. Ogunsalu C. A new surgical management for oro-antral communication: The resorbable guided tissue regeneration membrane-bone substitute sandwich technique. West Indian Med J. 2005; 54:261-3.

[11]. Yalçin S, Aybar B, Haznedaroğlu F, Yücel E. Bilateral oroantral fistulas following devitalization of teeth by arsenic trioxide: A case report. J Endod. 2003;29: 205-7.

[12]. Hauman CH, Chandler NP, Tong DC. Endodontic implications of the maxillary sinus: a review. Int Endod J. 2002 Feb;35(2):127141.

[13]. Van den Bergh JP, ten Bruggenkate CM, Disch FJ, Tuinzing DB. Anatomical aspects of sinus floor elevations. Clin Oral Implants Res. 2000 Jun; 11(3):256-65

[14]. Waldrop TC, Semba SE. Closure of oroantral communication using guided tissue regeneration and an absorbable gelatin membrane. J Periodontol. 1993 Nov; 64(11):1061-6. 
[15]. Gacic B, Todorovic L, Kokovic V, Danilovic V, Stojcev-Stajcic L, Drazic R, Markovic A. The closure of oroantral communications with resorbable PLGA-coated beta-TCP root analogs, hemostatic gauze, or buccal flaps: a prospective study. Oral Surg Oral Med Oral Pathol Oral Radiol Endod. 2009 Dec; 108(6):844-50.

[16]. Ngeow WC. The use of Bichat's buccal fat pad to close oroantral communications in irradiated maxilla. J Oral Maxillofac Surg. 2010 Jan; 68(1):229-30.

[17]. Hernando J, Gallego L, Junquera L, Villarreal P. Oroantral communications. A retrospective analysis.Med Oral Patol Oral Cir Bucal. 2010 May 1; 15(3):499-503.

[18]. Visscher SH, van Minnen B, Bos RR. Closure of oroantral communications using biodegradable polyurethane foam: a feasibility study. J Oral Maxillofac Surg. 2010 Feb; 68(2):281-6. 